\title{
Pengembangan Media Pembelajaran Fisika Berbasis Android Menggunakan Appypie dan Videoscribe pada Materi Momentum dan Impuls
}

Author(s): Achmad Rivai, Irnin Agustina Dwi Astuti, Indica Yona Okyranida, \& Dwi Aprillia Setia Asih

Editor: Helda Jolanda

Publication details, including author guidelines

URL: https://jlis.idcounselor.com/index.php/jlis/about/submissions

\section{Article History}

Received: $1 / 19 / 2021$

Revised: 3/4/2021

Accepted: 4/6/2021

\section{How to cite this article (APA)}

Rivai, A., Astuti, I. A. D., Okyranida, I. Y., \& Asih, D. A. S. . (2021). Pengembangan Media Pembelajaran Fisika Berbasis Android Menggunakan Appypie dan Videoscribe pada Materi Momentum dan Impuls. Journal of Learning and Instructional Studies, 1(1), 9-16. https://doi.org/10.46637/jlis.v1i1.2

The readers can link to article via https://doi.org/10.46637/jlis.v1i1.2

\section{SCROLL DOWN TO READ THIS ARTICLE}

Southeast Asia Mental Health and Counseling Association (as publisher) makes every effort to ensure the accuracy of all the information (the "Content") contained in the publications. However, we make no representations or warranties whatsoever as to the accuracy, completeness, or suitability for any purpose of the Content. Any opinions and views expressed in this publication are the opinions and views of the authors and are not the views of or endorsed by Southeast Asia Mental Health and Counseling Association. The accuracy of the Content should not be relied upon and should be independently verified with primary sources of information. Southeast Asia Mental Health and Counseling Association shall not be liable for any losses, actions, claims, proceedings, demands, costs, expenses, damages, and other liabilities whatsoever or howsoever caused arising directly or indirectly in connection with, in relation to, or arising out of the use of the content.

Journal of Learning and Instructional Studies is published by Southeast Asia Mental Health and Counseling Association comply with the Principles of Transparency and Best Practice in Scholarly Publishing at all stages of the publication process. Journal of Learning and Instructional Studies also may contain links to web sites operated by other parties. These links are provided purely for educational purpose.

\section{(c) (1)}

This work is licensed under a Creative Commons Attribution 4.0 International License.

Copyright by Rivai, et al (2021)

The author(s) whose names are listed in this manuscript declared that they have NO affiliations with or involvement in any organization or entity with any financial interest (such as honoraria; educational grants; participation in speakers' bureaus; membership, employment, consultancies, stock ownership, or other equity interest; and expert testimony or patent-licensing arrangements), or non-financial interest (such as personal or professional relationships, affiliations, knowledge or beliefs) in the subject matter or materials discussed in this manuscript. This statement is signed by all the authors to indicate agreement that the all information in this article is true and correct. 


\title{
Pengembangan Media Pembelajaran Fisika Berbasis Android Menggunakan Appypie dan Videoscribe pada Materi Momentum dan Impuls
}

\author{
Achmad Rivai $^{1 *}$, Irnin Agustina Dwi Astuti ${ }^{2}$, Indica Yona Okyranida ${ }^{3}$, \& Dwi Aprillia \\ Setia $\mathrm{Asih}^{4}$ \\ ${ }^{1}$ Sekolah Menengah Atas (SMA) Negeri 1 Maja, Lebak, Banten, Indonesia \\ 2,3,4 Universitas Indraprasta PGRI, Jakarta, Indonesia.
}

\begin{abstract}
The physics conception of momentum and impulse which illustrates many physics equations and abstracts allows it to be represented visually with Android-based physics learning media. The purpose of this study was to figure out the feasibility of Android based physics learning media using appypie and videoscribe. We adopt the ADDIE development model (Analysis, Design, Development, Implementation, and Evaluation) in this study. Learning media validation questionnaire sheets and student response tests were used to collect data. The findings of this study indicate that Android-based physics learning media are stated very feasible to be used in learning with an all validation average value of $84.41 \%$ and student response trials of $75.33 \%$. This Android-based physics learning media is an alternative solution for learning physics so that students can access learning material anytime and anywhere.
\end{abstract}

Key Words: Android-Based Leraning Media; Physics Learning; Appypie; Videoscribe.

Abstrak: Konsep fisika pada momentum dan impuls yang banyak menampilkan persamaan fisika dan abstrak memungkinkan ditampilkan secara visual degan media pembelajaran fisika berbasis android. Tujuan penelitian ini adalah untuk mengetahui kelayakan media pembelajaran fisika berbais android dengan menggunakan appypie dan videoscribe. Kami mengadopsi model pengembangan ADDIE (Analysis, Design, Development, Implementation, dan Evaluation) dalam studi ini. Lembar angket validasi media pembelajaran dan uji respon siswa digunakan untuk mengumpulkan data. Temuan studi ini menunjukkan bahwa media pembelajaran fisika berbasis android dinyatakan sangat layak untuk digunakan dalam pembelajaran dengan nilai rata-rata total validasi sebesar $84,41 \%$ dan uji coba respon siswa sebesar 75,33\%. Media pembelajaran fisika berbasis android ini merupakan solusi alternatif pembelajaran fisika sehingga siswa dapat mengakses materi pembelajaran kapanpun dan di manapun.

Kata Kunci: Media Pembelajaran Berbasis Android; Pembelajaran Fisika; Appypie; Videoscribe.

\footnotetext{
* Corresponding author: Achmad Rivai. SMA Negeri 1 Maja. Jl. Raya Maja No.1, Maja, Kec. Maja, Kabupaten Lebak, Banten 42381, Indonesia. Email: achmadrivai72@guru.sma.belajar.id
} 


\section{Pendahuluan}

Dunia pendidikan tidak terlepas dari proses pembelajaran yang meliputi guru, siswa, dan lingkungan pembelajaran yang saling mempengaruhi satu sama lain. Berkembangnya ilmu pengetahuan dan teknologi (IPTEK) yang begitu pesat, terutama media pembelajaran digital, para guru saat ini dapat menggunakan berbagai media ini dalam proses pembelajaran. Penggunaan media pembeljaran digital pun diterapkan dalam pembelajaran Fisika. Fisika adalah sebuah mata pelajaran yang menitikberatkan pada penguasaan konsep dalam penyelesaian permasalahannya. Oleh karena itu, penggunaan teknologi sebagai media pembelajaran perlu kiranya diterapkan dalam kegiatan belajar dan mengajar fisika. Pemilihan media pembelajaran yang berbasis teknologi harus disesuaikan dengan materi ajar dan kondisi sekolah seperti karakterirstik siswa dan guru (Mahnun, 2012). Penggunaan teknologi dalam kegiatan belajar dan mengajar sangatlah penting, karena dapat digunakan untuk menjelaskan materi pembelajaran dan dapat membantu guru dalam mengajar. Penggunaan media pembelajaran juga dapat meminimalisir sebuah kasus miskonsepsi pada siswa (Bastomi, Winarto, \& Purwaningsih, 2017).

Berdasarkan observasi di SMA Islam PB Soedirman Cijantung kelas X IPA 3 yang terdiri dari 24 siswa, mengenai kinerja guru fisika dan seputar keadaan siswa saat mengikuti pelajaran fisika di kelas, beberapa partisipan yang diajak berbincang dan diambil 10 orang secara acak, mereka menganggap bahwa pelajaran fisika di kelas cenderung sedikit membosankan, karena kurangnya penggunaan media pembelajaran yang digunakan dalam belajar fisika, walaupun sebenarnya disetiap ruangan kelas telah terinstalasi beberapa perangkat penunjang belajar seperti proyektor, koneksi Wi-Fi, dan penggunaan android. Namun pada pelaksanaanya, siswa malah salah persepsi dalam menggunakan fasilitas yang disediakan untuk hal yang kurang bermanfaat saat di dalam kelas dan proses pembelajaran berlangsung. Sembilan dari sepuluh orang responden yang diambil secara acak menyatakan bahwa mereka mengalami kesulitan dalam memahami materi momentum dan impuls terutama pada konsep kekekalan momentum dan membedakan beberapa jenis tumbukkan yang terjadi pada kasus fisika. Pada dasarnya siswa dapat membedakan beberapa tumbukkan, sudah saatnya mereka diberikan sebuah pengalaman yang nyata yang dapat diolah informasinya oleh indera mereka, salah satunya dengan menggunakan media pembelajaran yang berisi video pembelajaran terkait kasus jenis-jenis tumbukkan. Dalam meminimalisir permasalahan ini, seharusnya guru fisika membuat suatu siklus belajar yang melibatkan siswa berperan aktif dan memanfaatkan fasilitas apa saja yang diberikan sekolah untuk membantu proses belajar mengajar.

Dalam pembelajaran fisika, media pembelajaran yang mencakup materi-materi fisika sangat diperlukan. Hal ini dikarenakan bahwa fisika memerlukan pemahaman konsep yang tepat dalam menyelesaikan permasalahan-permasalahan yang timbul dari lingkup fisika itu sendiri. Pembelajaran yang digunakan sebelumnya harus diperbaiki berdasarkan hasil tes yang dilaksanakan setelah berakhirnya Kompetensi Dasar tiap materi yang telah diajarkan. Media pembelajaran dapat membuat siswa terlibat aktif dalam proses belajar-mengajar (Kumala \& Sumarni, 2020). Hal ini dimaksudkan bahwa media pembelajaran berperan sebagai stimulus untuk merespon minat siswa pada pelajaran fisika yang dianggap sebagai pelajaran yang rumit. Lagipula, siswa telah berperan aktif dalam proses belajar-mengajar, maka proses transfer pengetahuan akan lebih mudah dilakukan.

Banyak media pembelajaran yang bisa digunakan untuk menyampaikan materi pelajaran. Salah satunya adalah dengan menggunakan aplikasi videocribe dan appypie. Videscribe merupakan salah satu software yang digunakan dalma membuat video pembelajaran dengan menampilkan whiteboard animaton (Sakti, 2019). Kegunaan dari aplikasi videoscribe untuk membuat video pembelajaran, yang artinya kita dapat mengubah Journal of Learning and Instructional Studies (2021), 1(1), 9-16 https://doi.org/10.46637/jlis.v1i1.2 
materi fisika yang begitu rumit, menjadi sebuah video pembelajaran yang interaktif, yang mampu menarik minat siswa untuk belajar (Pratiwi, 2013). Adapun aplikasi appypie adalah sebuah aplikasi online yang disediakan dalam versi web. Aplikasi ini memiliki kegunaan untuk membuat aplikasi dalam bentuk android ataupun pc secara sederhana tanpa perlu menggunakan bahasa program (Rahmat, 2019). Hal ini akan memudahkan guru dalam memaksimalkan penggunan android untuk belajar, dan ini akan merespon minat siswa dalam belajar. karena perkembangan zaman yang sudah berbeda, sehingga membuat guru harus bisa menguasai penggunaan teknologi.

\section{MetOde}

Penelitian ini merupakan Penelitian Pengembangan (Research \& Development). Prosedur penelitian yang digunakan adalah dengan model ADDIE yaitu model pengembangan yang terdiri dari lima tahapan yang terdiri dari analysis (analisis), design (desain), development (pengembangan), implementation (implementasi), dan evaluating (evaluasi) (Sugiyono, 2015). Instrumen penelitian yang akan digunakan dalam penelitian ini berupa angket. Angket pada penelitian ini diberikan kepada ahli materi, ahli media, dan responden (siswa). Angket ini digunakan sebagai instrumen penelitian untuk mengetahui kelayakan media pembelajaran fisika berbasis android. Kisi-kisi yang digunakan untuk menilai media pembelajaran terlihat pada tabel 1 dan tabel 2 .

Tabel 1. Kisi-kisi Instrumen Validasi oleh Ahli Materi

\begin{tabular}{clcc}
\hline No. & \multicolumn{1}{c}{ Indikator } & Nomor Item & Jumlah Item \\
\hline 1. & Aspek Kebahasaan & $1,2,3$ & 10 \\
2. & Aspek Kesesuaian Materi & $4,5,6,7,8,9,10,11$ & 2 \\
3 & Aspek Ilustrasi & $12,13,14$ & 3 \\
\hline
\end{tabular}

Tabel 2. Kisi-kisi Instrumen Validasi oleh Ahli Media

\begin{tabular}{llcc}
\hline No. & \multicolumn{1}{c}{ Indikator } & Nomor Item & $\begin{array}{c}\text { Jumlah } \\
\text { Item }\end{array}$ \\
\hline 1. & Aspek Grafika & $1,2,3,4,5,6,7,8,9,10$ & 10 \\
2. & Aspek Pengolahan Program & 11,12 & 2 \\
3 & Aspek Penggunaan & $13,14,15$ & 3 \\
\hline
\end{tabular}

Selanjutnya, penilaian kelayakan produk diuji dan dinilai oleh validator yaitu ahli media dan ahli materi. Kelayakan produk dianalisis dengan menggunakan instrumen kuesioner dengan skala likert. Kategori jawaban yang disediakan berupa sangat setuju (SST), setuju (ST), tidak setuju (TS), sangat tidak setuju (STS). Jawaban kuesioner diberi bobot 4,3,2,1 untuk pernyataan positif dan 1,2,3,4 untuk pernyataan negatif. Teknik analisis data yang digunakan adalah analisis deskriptif dan analisis rata-rata. Hasil validasi media pembelajaran fisika dirata-rata untuk dilihat hasilnya apakah sudah layak atau belum. Kriteria kelayakan media pembelajaran dapat dilihat pada Tabel 3.

Tabel 3. Kriteria kelayakan media pembelajaran

\begin{tabular}{lcc}
\hline & Skor Kuesioner & Kriteria \\
\hline $81,25 \%<$ skor $\leq 100 \%$ & Sangat baik \\
$62,50 \%<$ skor $\leq 81,25 \%$ & Baik \\
$43,75 \%<$ skor $\leq 62,50 \%$ & Cukup baik \\
$25 \%<$ skor $\leq 43,5 \%$ & Kurang baik \\
\hline
\end{tabular}

Southeast Asia Mental Health and Counseling Association

https://doi.org/10.46637/jlis.v1i1.2 


\section{HASIL DAN DISKUSI}

Produk yang dihasilkan dari penelitian pengembangan ini berupa media pembelajaran berbasis android menggunakan appypie dan sparkol. Pengembangan media pembelajaran ini menggunakan model pengembangan ADDIE. Model ADDIE memiliki 5 tahapan antara lain Analysis (Analisis), Design (Desain), Development (Pengembangan), Implementation (Implementasi) dan Evaluation (Evaluasi).

Tahap analisis dilakukan analisis awal terhadap karakter siswa, analisis materi, dan analisis kebutuhan. Analisis karakter siswa ditinjau dari kondisi siswa saat proses pembelajaran berlangsung. Berdasarkan analisis karakter siswa diperoleh beberapa kondisi siswa yaitu kurang aktif dan mandiri dan hanya mengandalkan referensi dari guru dalam proses pembelajaran. Di samping itu, guru kurang memanfaatkan sarana dan prasarana dengan baik, sehingga masih sedikit guru yang menggunakan media pembelajaran di kelas. Analisis materi dilakukan dengan cara mengidentifikasi materi utama yang perlu diajarkan, mengumpulkan dan memilih materi yang relevan dan menyusun secara sistematis dalam bentuk media pembelajaran berbasis android. Dalam penelitian ini pokok bahasan yang dipilih adalah momentum dan impuls.

Pada tahap design, media pembelajaran berbasis android dibuat dengan menggunakan app online builder yaitu appypie. Selain, videoscribe sparkol digunakan untuk menambahkan video pembelajaran yang ada di dalam media pembelajaran berbasis android tersebut. Media pembelajaran berbasis android di desain semenarik mungkin agar memiliki daya tarik dan minat belajar oleh siswa. Pada tahap ini membuat kerangka isi media pembelajaran berbasis android, seperti menyiapkan materi, latihan soal, evaluasi, video pembelajaran, background, warna, dan menu interaktif. Tampilan rancangan atau desain media pembelajaran fisika berbasis android dapat dlihat pada gambar 1 .

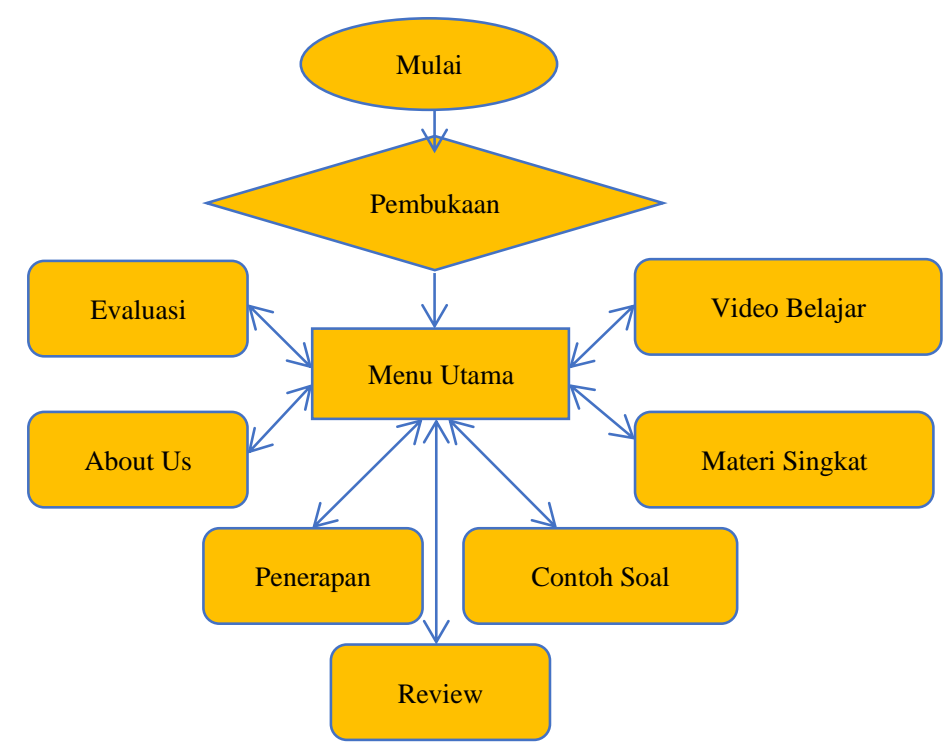

Gambar 1 Desain Media Pembelajaran Berbasis Android

Pada tahap development (pengembangan), membuat isi atau konten media pembelajaran berbasis android. Setelah media pembelajaran berbasis android selesai dibuat maka langkah selanjutnya adalah memvalidasi media pembelajaran berbasis android ke validator yang ahli di bidangnya. Data hasil validasi ahli materi dan ahli media dapat dilihat pada Tabel 4 dan Tabel 5. 
Tabel 4. Validasi Ahli Materi

\begin{tabular}{cc}
\hline Ahli Materi & Skor (\%) \\
\hline Validator 1 & 67,86 \\
Validator 2 & 96,43 \\
Rata-rata validasi materi & 82,14 \\
\hline
\end{tabular}

Berdasarkan data hasil perhitungan yang didapat dari uji validasi ahli materi diperoleh nilai rata-rata validasi sebesar 82,14\%, yang memiliki kriteria skor 'Sangat Baik'.

Tabel 4. Validasi Ahli Media

\begin{tabular}{cc}
\hline Ahli Media & Skor (\%) \\
\hline Validator 1 & 95 \\
Validator 2 & 78.33 \\
Rata-rata validasi media & 86,67 \\
\hline
\end{tabular}

Berdasarkan data hasil perhitungan yang didapat dari uji validasi ahli media diperoleh nilai rata-rata validasi sebesar $86,67 \%$, yang memiliki kriteria skor 'Sangat Baik'. Tahap berikutnya yaitu implementasi. Pada tahap ini dilakukan uji coba kelas kecil ke siswa. Setelah melaukan uji validasi media pembelajaran fisika berbasis android maka langkah selanjutnya yaitu uji cba kelas kecil. Responden yang digunakan dalam penelitian ini adalah siswa kelas $\mathrm{X}$ SMA Islam PB Soedirman Cijantung.

Kelebihan aplikasi yang didapat dalam penelitian ini adalah aplikasi ini memiliki kemampuan user friendly bagi para siswa yang baru mengoperasikannya, bahkan penilaian uji kognitif yang bersifat $C B T$ membuat guru lebih mudah merangkum data nilai siswa. Selain itu, aplikasi ini juga digunakan untuk mengukur kemampuan siswa secara obyektif melalui video pembelajaran untuk memperjelas siswa dalam memahami materi yang belum dipahami sebelumnya. Aplikasi media pembelajaran ini juga tergolong dalam aplikasi yang cukup ringan dan lebih mudah diunduh pada smartphone siswa. Responden yang digunakan berjumlah 14 orang dengan hasil rata-rata sebesar 75,33\%.

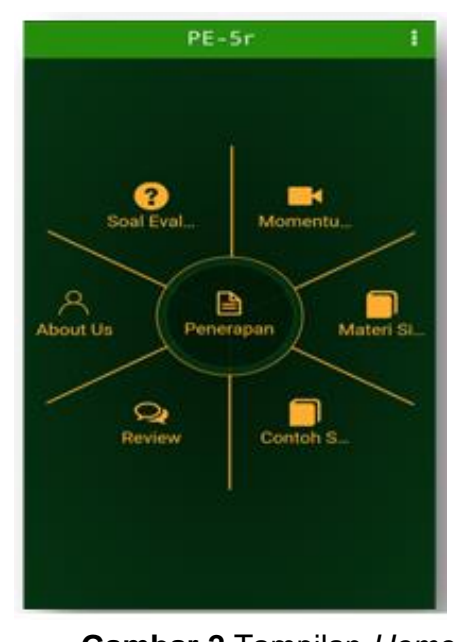

Gambar 2 Tampilan Home

Gambar 2 adalah tampilan home (muka) pada media pembelajaran fisika berbasis android. Pada tampilan ini berisi beberapa konten yang disajikan dalam aplikasi ini. Konten yang disajikan dalam aplikasi ini adalah, video pembelajaran, soal evaluasi, penerapan, contoh soal, materi singkat. Namun pada aplikasi ini lebih dititikberatkan dalam video 
pembelajaran sebagai pemeran utamanya. Video pembelajaran ini dihubungkan langsung kedalam youtube, sehingga aplikasi ini harus dijalankan dalam keadaan online.

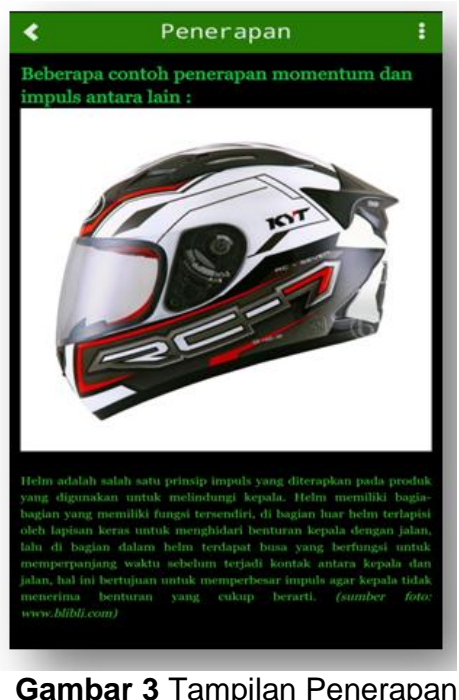

Pada menu penerapan berisi materi fisika yang dihubungkan atau diterapkan dalam kehidupan sehari-hari. Penerapan materi momentum dan impuls seperti yang terlihat pada gambar 3 ditampilkan beberapa contoh penerapan kasus momentum dan impuls dalam kehidupan sehari-hari yang jarang diketahui oleh siswa. Menu ini menunjukkan kepada siswa manfaat mempelajari ilmu fisika dalam kehidupan sehari-hari bahkan dengan belajar fisika, mereka dapat menciptakan sesuatu yang memiliki nilai manfaat di kemudian hari.

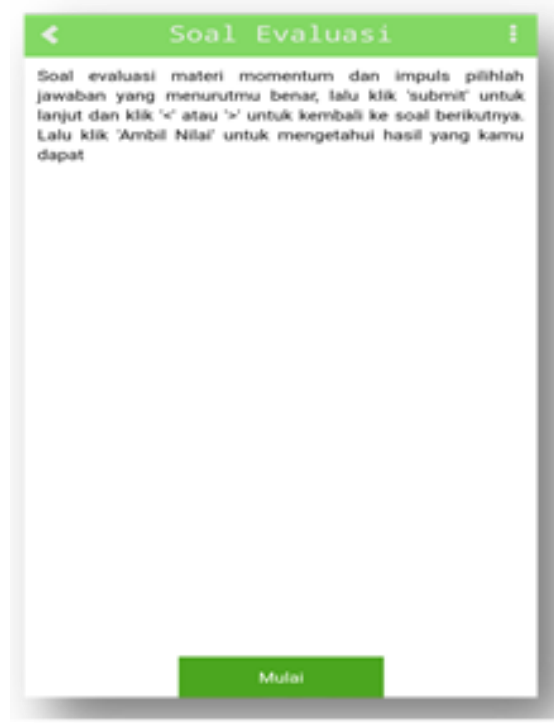

Gambar 4 Tampilan Evaluasi

Pada menu evaluasi ditampilkan sebuah media evaluasi yang bersifat CBT (Computer Basic Test), seperti yang terlihat pada gambar 4. Pada menu ini, guru tidak lagi menilai hasil kerja siswa secara manual, namun siswa hanya perlu mengisi soal seperti biasanya dan secara langsung sistem akan memproses perintah yakni hasil siswa dalam bentuk nilai dan standar kelulusan yang memang sudah didisain sedemikian rupa oleh peneliti. Kemudian hasil yang telah diperoleh dapat dibagikan melalui media-media yang lain. 
Pengembangan aplikasi media pembelajaran berbasis android interaktif ini bertujuan untuk mendesain dan membuat media pembelajaran yang memenuhi karakteristik dan kualitas media pembelajaran yang baik agar dapat digunakan oleh siswa. Hal ini di dorong oleh motivasi dan minat siswa dalam belajar fisika yang masih kurang dan cenderung menggunakan smartphone hanya untuk komunikasi dan hiburan. Kecenderungan siswa dalam belajar fisika lebih mengarah kepada pembelajaran yang kurang bermakna, karena cara berpikir yang menunjukkan tidak ada bukti konkretnya saat mereka mempelajari mata pelajaran fisika. Oleh karena itu, pembelajaran fisika membutuhkan sebuah media interaktif dan inovatif untuk menyampaikan informasi menjadi lebih efisien, kreatif dan bermanfaat.

Penggunaan media yang baik akan memberikan dampak positif yang sangat besar bagi penggunanya, terlebih bila hal ini diimplementasikan dalam pembelajaran fisika khususnya dan umumnya dalam bidang pendidikan. Pembuatan media pembelajaran ini melibatkan beberapa penggunaan aplikasi dan sistus web, yaitu videoscribe dan appypie. Pemanfaatan teknologi dalam media pembelajaran mempunyai peran penting agar media pembelajaran dapat ditampilkan dengan baik. Hal ini di dukung oleh beberapa pendapat bahwa media pembelajaran berbasis android dapat digunakan dalam mendukung pembelajaran fisika. Hal ini selaras juga dengan penelitian Dasmo, Astuti \& Nurullaeli (2017), media pembelajaran berbasis android dapat meningkatkan pemahaman konsep fisika. Media pembelajaran berbasis android merupakan salah satu inovasi media pembelajaran fisika yang sesuai dengan perkembangan jaman dan teknologi. Dengan menggunakan media pembelajaran berbasis android siswa akan merasakan kemudahan mempelajari materi fisika menggunakan smartphone (Dewi, Astra, \& Susanti, 2018; Rahmat et al, 2019).

Penggunaan media yang tepat akan membuat siswa belajar dengan mudah dan merasa senang dalam mengikuti pembelajaran. Salah satu hal yang perlu dicermati adalah keterkaitan antara media pembelajaran dan perkembangan teknologi dan komunikasi yang semakin maju. Wicaksono dan Hakim (2013) mengemukakan bahwa, media pembelajaran adalah solusi yang dapat digunakan oleh guru dalam mengajar. Dengan media pembelajaran, guru dapat menjelaskan suatu materi dengan model, foto, atau video tentang obyek yang dijelaskan.

Penggunaan appypie sangat mudah diterapkan untuk membuat suatu media pembelajaran dikarenakan sangat simple dan mudah diakses secara gratis. Appypie merupakan aplikasi online builder yang bisa dikerjakan untuk mebuat aplikasi android secara online. Menurut Astuti, Dasmo, Sumarni (2018), kelebihan appypie dibanding aplikasi yang lain yaitu tidak memerlukan koding (bahasa pemrograman) dalam membuat aplikasi, menyediakan templatedalam pembuatan aplikasi android secara gratis dan ukuran file tidak terlalu besar sehingga mudah dioperasikan dismartphone.

Penggabungan appypie dan videoscribe menjadi suatu inovasi baru sebagai media pembelajaran fisika. Selain itu, Videocsribe digunakan untuk menampikan video pembelajaran fisika yang dihubungkan ke appypie. Videocribe dapat menampilkan konsep fisika secara audio visual sehingga dapat meningkatkan pemahaman konsep siswa (Bhakti, Astuti, \& Rahmawati, 2020). Dengan tampilan video yang kompleks dan dijelaskan secara rinci, videoscribe dapat menjadi alternatif siswa dalam mempelajari fisika agar tidak bosan (Jannah, Harijanto, \& Yushardi, 2019; Rubiyah, Dasmo, Suhendri, 2020).

\section{SIMPULAN}

Berdasarkan analisis data hasil penelitian maka diperoleh nilai rata-rata validasi dari ahli materi dan ahli media sebesar $82,14 \%$ dan $86,67 \%$. Hal ini menunjukkan bahwa media pembelajaran fisika berbasis android layak digunakan dengan skor rata-rata total sebesar 84 , $41 \%$ dengan kategori sangat baik. Maka dapat disimpulkan bahwa pada bagian materi 
memiliki kriteria skor 'Sangat Baik' dan hasil uji coba respon siswa diperoleh 75,33\%. Hasil ini menunjukkan bahwa siswa sangat antusias dan tertarik belajar fisika dengan menggunakan media pembelajaran berbasis android menggunakan appypie dan videoscribe.

\section{References}

Astuti, I. A. D., Dasmo, D., \& Sumarni, R. A. (2018). Pengembangan Media Pembelajaran Berbasis Android dengan Menggunakan Aplikasi Appypie di SMK Bina Mandiri Depok. Jurnal Pengabdian Kepada Masyarakat, 24(2), 695-701.

Bastomi, K., Winarto, W., \& Purwaningsih, E. (2017). Pengembangan media pembelajaran interaktif untuk mengurangi miskonsepsi pada materi usaha dan energi. In Seminar Nasional Fisika dan Pembelajarannya.

Bhakti, Y. B., Astuti, I. A. D., \& Rahmawati, E. Y. (2020). Improving Students' Problem Solving Ability Through Learning Based Videoscribe. JIPF (Jurnal Ilmu Pendidikan Fisika), 5(2), 61-67.

Dasmo, Astuti, I.A.D., \& Nurullaeli. (2017). Pengembangan Pocket Mobile Learning Berbasis Android. Jurnal Riset dan Kajian Pendidikan Fisika, 4 (2), 1-7.

Dewi, D. K., Astra, I. M., \& Susanti, D. (2018). Buku suplemen berbasis android sebagai media pembelajaran pada materi gelombang elektromagnetik untuk peserta didik SMA. In PROSIDING SEMINAR NASIONAL FISIKA (E-JOURNAL) (Vol. 7, pp. SNF2018-PE).

Jannah, M., Harijanto, A., \& Yushardi, Y. (2019). Aplikasi Media Pembelajaran Fisika Berbasis Sparkol Videoscribe Pada Pokok Bahasan Suhu Dan Kalor Terhadap Hasil Belajar Siswa SMK. Jurnal Pembelajaran Fisika, 8(2), 65-72.

Mahnun, N. (2012). Media pembelajaran (kajian terhadap langkah-langkah pemilihan media dan implementasinya dalam pembelajaran). An-Nida', 37(1), 27-34.

Kumala, S. A., \& Sumarni, R. A. (2020). Pengembangan Media Pembelajaran Menggunakan Uno Stacko Pada Materi Fisika Kelas X. Navigation Physics: Journal of Physics Education, 2(1), 14-20.

Pratiwi, E. D. (2017). Pengembangan Media Pembelajaran Fisika Berbasis Sparkol VideoScribe Pokok Bahasan Kinematika Gerak di Perguruan Tinggi. (Skripsi). Sekolah Sarjana, Universitas Islam Negeri Raden Intan, Lampung.

Rahmat, H. K. (2019). Mobile Learning Berbasis Appypie sebagai Inovasi Media Pendidikan untuk Digital Natives dalam Perspektif Islam. Tarbawi: Jurnal Pendidikan Islam, 16(1).

Rahmat, R. F., Mursyida, L., Rizal, F., Krismadinata, K., \& Yunus, Y. (2019). Pengembangan media pembelajaran berbasis mobile learning pada mata pelajaran simulasi digital. Jurnal Inovasi Teknologi Pendidikan, 6(2), 116-126.

Rubiyah, S., Dasmo, D., \& Suhendri, H. (2020). Pengembangan Media Pembelajaran Fisika Berbasis Sparkol Videoscribe dan AVS Video Editor Untuk Siswa Kelas X SMK Mahadhika 2 Jakarta Timur. Schrodinger Jurnal Ilmiah Mahasiswa Pendidikan Fisika, 1(2), 107-118.

Sakti, I. (2019). Pengaruh Penggunaan Media Pembelajaran Berbasis Videoscribe Terhadap Pemahaman Konsep Fisika Siswa SMP Ittihad Makassar. PHYDAGOGIC Jurnal Fisika dan Pembelajarannya, 1(2), 49-54.

Wicaksono, D. S., \& Hakim, F. N. (2013). Media Pembelajaran Fisika Interaktiv Bahasan Kapasitor Berbasis Flash Dan XML.Speed-Sentra Penelitian Engineering dan Edukasi, 3(2). 